\title{
Fetoscopy Role in Fetal Surgery and Fetal Medicine
}

\author{
Wael S. S. Elbanna ${ }^{1 *}$, Ibrahim A. Oun1, Emad M. Abd Ellatif ${ }^{1}$, Wael R. Hablas ${ }^{2}$, Walid I. El Shaikh'1, \\ Yehia A. Wafa ${ }^{1}$
}

${ }^{1}$ Department of Obstetrics \& Gynecology, Al-Azhar University, Cairo, Egypt

${ }^{2}$ Department of Clinical Pathology, Al-Azhar University, Cairo, Egypt

Email: *dr.wael.ss.elbanna@gmail.com

How to cite this paper: Elbanna, W.S.S., Oun, I.A., Ellatif, E.M.A., Hablas, W.R., El Shaikh, W.I. and Wafa, Y.A. (2019) Fetoscopy Role in Fetal Surgery and Fetal Medicine. Open Journal of Obstetrics and $G y$ necology, 9, 1477-1485.

https://doi.org/10.4236/ojog.2019.911143

Received: October 23, 2019

Accepted: November 8, 2019

Published: November 11, 2019

Copyright (c) 2019 by author(s) and Scientific Research Publishing Inc. This work is licensed under the Creative Commons Attribution International License (CC BY 4.0).

http://creativecommons.org/licenses/by/4.0/

\begin{abstract}
Aim: We attempted to illustrate our experience of fetoscopic therapy in a tertial institute, whereby to highlight the present Egyptian situation regarding this issue. We described fetoscopic therapy undergone at Al-Hussein Hospital, Al-Azhar University, Cairo, Egypt, from Dec-2012 to Sep-2019. Presentation of cases: Sixteen women with 17 fetuses were included in the analysis of this study with a mean age of $25.31 \pm 6.15$ years; four with positive marriage to a near relevant, and eight were primigravida. The fetus of twelve women had lower urinary tract obstruction (LUTO), two fetal anemia, one hydrothorax, and one twin-to-twin transfusion syndrome (TTTS). The mean time for fetoscopy was gestational week $24.13 \pm 3.77$. We did therapeutic drainage to amniotic fluid in hydrothorax and LUTO, therapeutic septostomy to the TTTS case, and blood transfusion in cases of fetal anemia. During the operation, the procedure succeeded in 14 out of 16 women. Overall, nine of the 16 women experienced some complications; five with rupture of membranes, four with preterm labor, and three with intrauterine fetal death (IUFD). Conclusion: Fetoscopy can manage LUTO and well-selected cases of TTTS, hydrothorax, and fetal anemia. The procedure is promising. Fetoscopic therapy has just begun in Egypt, and this report may contribute to the future advance of fetoscopic therapy in Egypt.
\end{abstract}

\section{Keywords}

Fetoscopy, Lower Urinary Tract Obstruction, LUTO, Twin-to-Twin Transfusion Syndrome, Fetal Anemia, Complications Rate

\section{Introduction}

Due to the advances in prenatal diagnostic procedures, the examination of con- 
genital fetal anomalies becomes feasible, with some of them are amenable for management thanks to the development of fetoscopy and fetoscopic surgeries with all its emerging instrumentation armamentarium [1] [2].

During the first two decades of the new millennium, in-utero management of these anomalies became feasible due to the evolution of fetoscopy and the extended role of fetoscopic surgeries. Also, the progress of fetoscopic surgeries became prominent in the treatment of some fetal anomalies like lower urinary tract obstruction (LUTO), hydrothorax, and fetal anemia [3]-[11].

In our region, the Middle East, we lack such technology and expertise, with a few studies about fetoscopy. Since establishing the first program for fetoscopy for fetal blood sampling in 1981, another study in 2015 was conducted to evaluate the laser coagulation for severe TTTS in one center in UAE. Then, a third study, which considered the first trial to evaluate the role of fetoscopy in different types of congenital anomalies, was conducted in a private center in Cairo, Egypt, upon twenty patients with 22 fetuses [12] [13] [14]. Added to the previous data, in our country Egypt, congenital anomalies are highly prevalent [15] [16]. Thus, the rationale intended for this research was to evaluate the fetoscopy role in the management of certain congenital anomalies as the first trial in one of the Egyptian universities at Al-Hussein Hospital, Al-Azhar University in Cairo. Therefore, this case-series study aimed to evaluate, discuss, and illustrate the role of fetoscopy in our governmental setting.

\section{Patients and Methods}

This case-series study was conducted in the Obstetrics and Gynecology department of Al-Hussein Hospital, Al-Azhar University, Cairo, Egypt, from December 2012 to September 2019. The study conformed to the national laws and regulations of the institution, and an ethical committee approval was obtained from the institution. Sixteen pregnant women from 19 weeks of gestation having congenital fetal malformations and willing to undertake fetoscopy, were enrolled. Exclusion criteria were: refusal to participate; women with a comorbid medical condition; Rh-negative women, women with any prepartum rupture of membrane or bleeding. Written informed consent was obtained after an explanation of the procedure and approval of the enrolled women. Detailed obstetric history and examination were done. Serum panel, coagulation profile, liver, and kidney function tests were made. Imaging by ultrasound was used to confirm the diagnosis. Thus, evaluation of the position, the lie of the fetus can be made. Besides, investigation of any comorbid conditions, and intrauterine mapping to make a mark for entry, can be achieved.

All patients were sedated using iv midazolam $0.02 \mathrm{mg} / \mathrm{kg}$. After the application of ASA-standard monitors, anesthesia was induced using fentanyl $2 \mathrm{mg} / \mathrm{kg}$, followed by propofol $2 \mathrm{mg} / \mathrm{kg}$, and then atracurium besylate $0.5 \mathrm{mg} / \mathrm{kg}$, and maintained by isoflurane $2 \%$. After recovery, they were transferred to a specialized care unit. 
Semi-rigid $0^{\circ}$ straightforward miniature endoscope, 1 - $3.6 \mathrm{~mm}$ in diameter (Karl Storz fetoscopes), is used. In order to facilitate the suction and irrigation procedure, the needle-scope is connected to the 18 gauge trocar via a lateral female Lure-lock adaptor. Fetal monitoring was done during and after the procedure by US \& Doppler (Fetal heart rate, umbilical artery Doppler).

\section{Procedures and follow up}

We performed an ultrasound to identify the fetal position as well as the placental site. That was to help to mark a point-of-entry for the fetoscope. The trocar and cannula were introduced via a $3-\mathrm{mm}$ incision in the abdomen and uterine wall to get into the amniotic cavity under ultrasound guidance. After that, we removed the cannula and introduced the fetoscope through the trocar to examine the fetal parts, including the face, limbs, abdominal wall, and umbilical cord insertion, the back (Figure 1). Whenever possible, we investigated the placenta for vessels or any abnormalities. We noted the clarity of vision, intra-amniotic

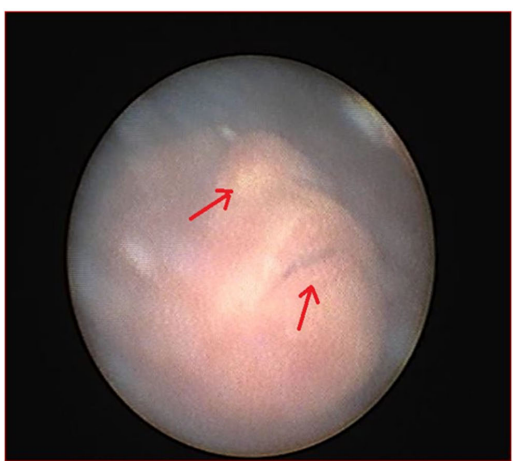

Mouth and nose of the fetus

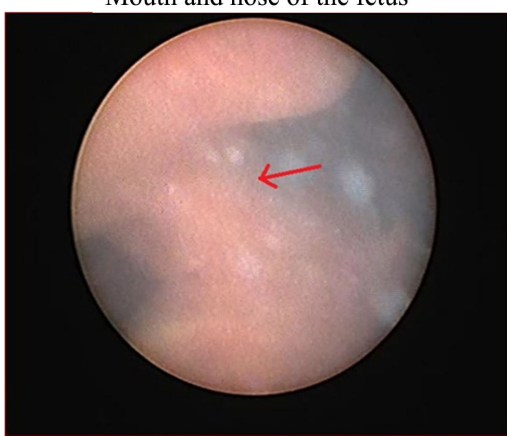

Neck of the fetus

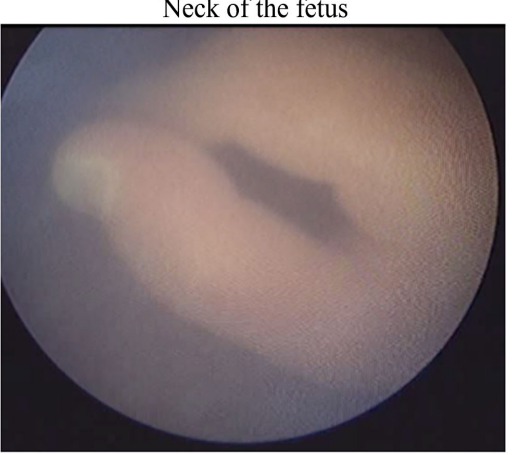

Thumb of the fetus

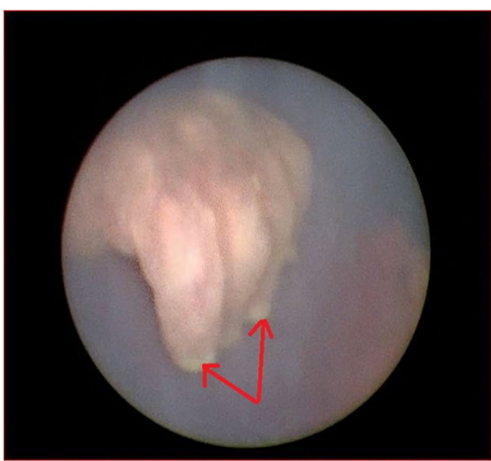

Hand fingers of the fetus

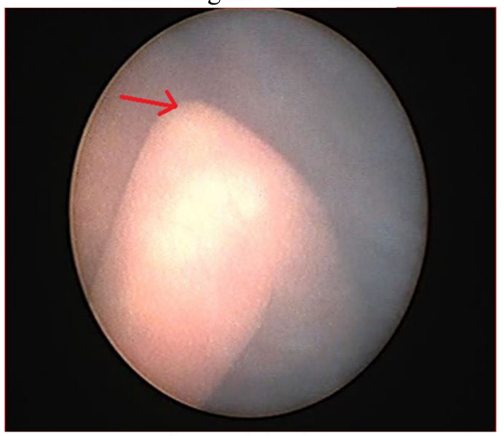

Elbow of the fetus

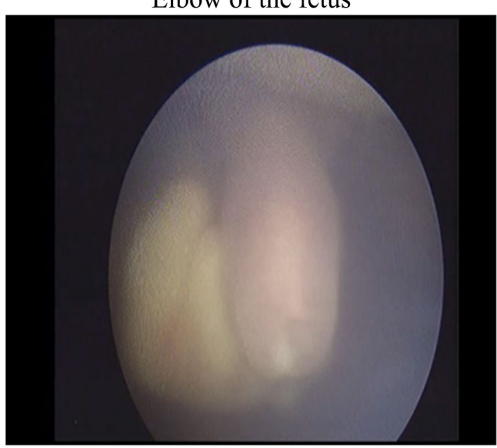

Penis of the fetus

Figure 1. Fetoscopic images mapping of the fetus (different body parts). 
bleeding, or any procedural problems. A continuous ringer lactate amnioinfusion system was used to maintain visibility while monitoring the volume infused. Each congenital anomaly was dealt with accordingly, and corrections of the underlying conditions were made.

\section{Presentation of the Cases}

\section{Baseline characteristics:}

The mean age of patients was $25.31 \pm 6.15$ years with a range of $18-41$. A Positive marriage to a near relevant was found in only four women. Eight patients $(50 \%)$ were primigravida. One patient had one normal vaginal delivery (NVD), and one had three NVD. One patient had one CS, two had two CS, and two had three CS. One patient had one previous abortion, and another one had three previous abortions. Nine patients (56.25\%) had no live kids; two had one live kid (12.50\%); two had two live kids (12.50\%), and three had three live kids $(18.75 \%)$.

None of the women has been taken any ovulation induction or got pregnant by assisted reproductive technique. Also, none of them has been taken any teratogenic medication. The fetus of twelve women had LUTO, two fetal anemia, one hydrothorax, and one TTTS.

The mean time for fetoscopy was gestational week $24.13 \pm 3.77$, with a minimum of 19.0 and a maximum of 31 weeks.

On-the-table success rate:

On the table, the fetoscopy succeeded in the correction of the underlying fetal condition in fourteen $(87.5 \%)$ of cases with no recurrence after fetoscopy (Table 1).

\section{Post-fetoscopy complications:}

Overall, nine (56.25\%) of the 16 patients experienced some complications. Rupture of membranes was diagnosed in five (31.25\%) patients, and chorioamnionitis did not occur in any of them. Preterm labor occurred in four patients $(25.00 \%)$, and IUFD occurred in three patients (18.75\%), as shown in Table 2.

From 17 fetuses included in our study, three fetuses died in utero due to recurrence, one within one week and two within one month of the surgery, and another four died after birth primarily from complications of prematurity.

Table 1. The on-going success rate of fetoscopy in each congenital anomaly.

\begin{tabular}{ccccc}
\hline & \multirow{2}{*}{$\begin{array}{c}\text { Number of patients } \\
\text { with the condition }\end{array}$} & \multicolumn{2}{c}{ Success } & p-value \\
\cline { 3 - 5 } & 12 & $\mathrm{n}$ & $\%$ & \\
\hline PUV & 2 & 11 & $91.67 \%$ & \\
Fetal anemia & 1 & 1 & $50.00 \%$ & \\
Hydrothorax & 1 & 1 & $100.00 \%$ & 0.384 \\
TTTS & 16 & 1 & $100.00 \%$ & \\
Grand total & 16 & 14 & $87.50 \%$ & \\
\hline
\end{tabular}


Table 2. Post-fetoscopy complications.

\begin{tabular}{cccc}
\hline & & Number & Percentage \\
\hline \multirow{2}{*}{ Preterm labor } & PUV & 3 & $18.75 \%$ \\
& TTTS & 1 & $6.25 \%$ \\
& & 4 & $\mathbf{2 5 . 0 0 \%}$ \\
\hline \multirow{2}{*}{ IUFD } & Fetal anemia & 2 & $12.5 \%$ \\
& PUV & 1 & $6.25 \%$ \\
PROM & & 3 & $18.75 \%$ \\
\hline & PUV & 4 & $25.00 \%$ \\
& TTTS & 1 & $6.25 \%$ \\
\hline
\end{tabular}

\section{Discussion}

Over the past few years, interest in fetal intervention has become widespread. Fetoscopy is just very new and has consolidated its position in fetal medicine in a few experienced centers in the world in the past three decades. That is because of the advances in diagnosis, insight into the pathophysiology of congenital anomalies amenable to fetal surgery, as well as the technical innovations in endoscopic equipment. Now, fetoscopic interventions are beneficial as a therapeutic tool for treating several fetal anomalies like lower urinary tract obstruction, congenital diaphragmatic hernia, cardiac defects, and TTTS [11].

The results of this study demonstrated that fetoscopy had been succeeded in the management of all cases. Therapeutic drainages of hydrothorax to the amniotic fluid were done successfully. Also, in cases of PUV, therapeutic drainages of the bladder to the amniotic fluid were done successfully in all. Also, fetoscopy succeeded in the mapping of arteriovenous vessels on the surface of the twin placenta in TTTS. Moreover, fetoscopy succeeded in blood transfusion in both cases of fetal anemia. Eight of the women showed some complications. Therefore, women must be counseled regarding the risks and benefits of endoscopic fetal surgery.

The overall safety of the mothers was excellent in this research study; nevertheless, the preterm delivery and the PROM are the most frequent problems faced, which is similar to that reported in the literature elsewhere [1] [14] [17].

The results of our study on PUV cases showed that almost all cases (partial PUV and complete PUV) were improved during the follow-up period (Figure 2). Some of them developed no complications. The drainage of the bladder to the amniotic fluid was successful by fulguration and flushing in all cases. Successful management of PUV cases has been reported in other studies [14] [18] [19] [20] [21]. In those cases of PUV, the earlier the intervention, the better is the prognosis because the mega-bladder may lead to compression of the heart. Fulguration by different tools, guide wires or graspers; lead to the achievement of urethral patency, and we can see the bladder deflates its wall on fetoscopy. 


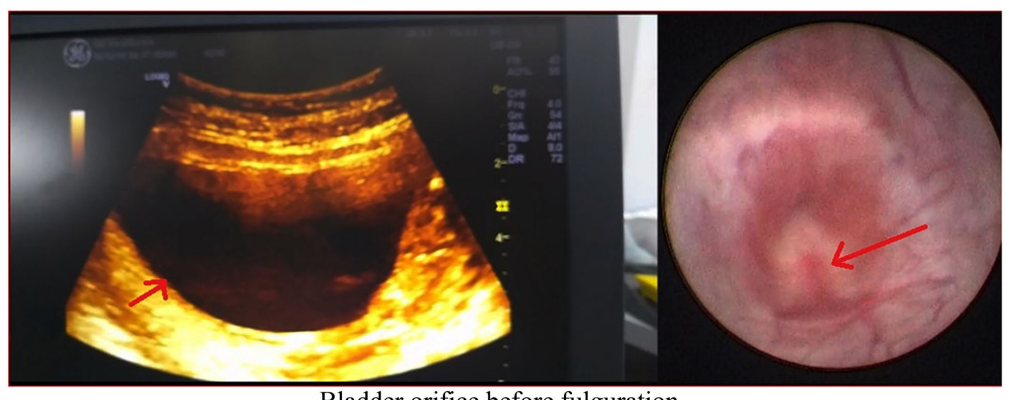

Bladder orifice before fulguration
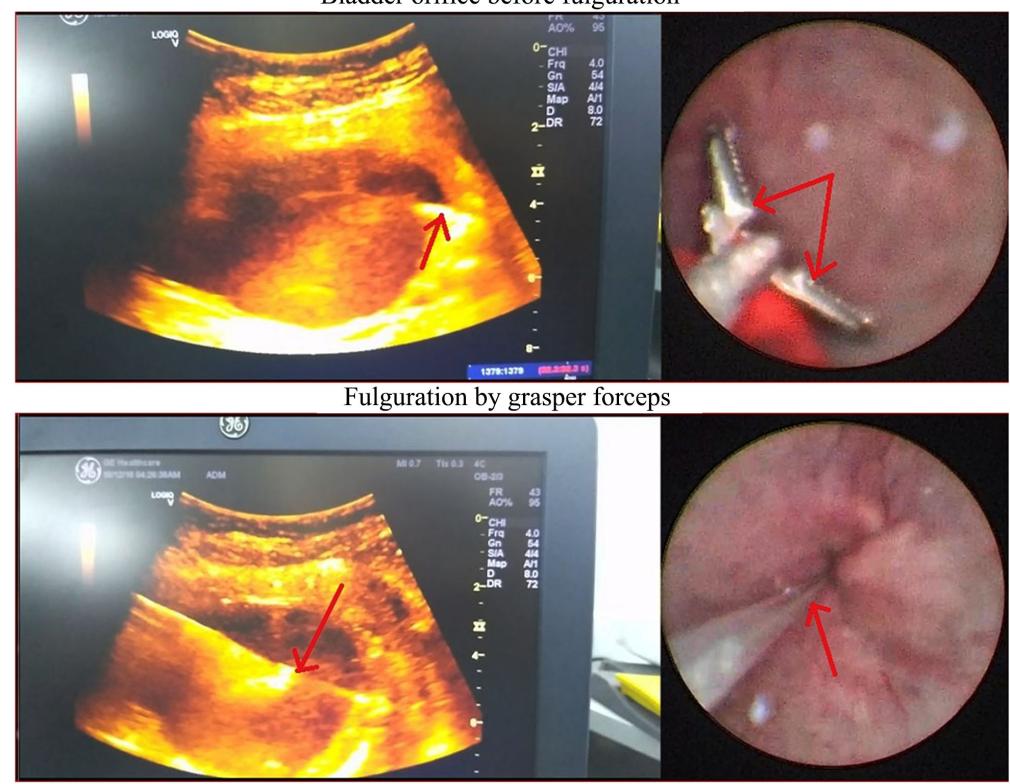

Fulguration by grasper forceps

Figure 2. PUV: steps of the procedure.

Proximal ureteric obstruction may be diagnosed as PUV and operated upon without any success [22]. Nevertheless, in our study, we did not face this condition. The degree of renal failure has to be detected by assessing the fetal $\mathrm{Na}, \mathrm{K}$, and microalbuminuria in the fetal urine sample taken by the fetoscope.

In our experience, one of the challenges we faced was the twin to twin transfusion syndrome. The right thing to do for those cases is the mapping to help go from the sac of the recipient fetus to the donor because the first has a significant amount of amniotic fluid. Thus, we go with a fetoscope inside the sac of the recipient and search for the donor. There will always be a membrane separating both fetuses, which is covering the donor. We did septostomy in all cases.

A retrospective review of patients who were diagnosed with twin-twin transfusion syndrome showed a statistically significant prolongation of pregnancy for septostomy compared to amnioreduction [23].

We tried to use fetoscopic surgery in hydrothorax. To make a suction of the fluid in a way that we can adjust and can see, of course, we can use US guidance. However, sometimes, the fetoscopist may injure any adjacent structure like the arms or the cord. In these challenging cases, a fetoscope was used to search for the chest wall and determine the direction we will go through. That is one of the 
advantages of using fetoscopy-guided suction for hydrothorax. The patient gets immediate results. The lung inflates, and the restriction to the heart is relieved (Figure 3).

Petersen et al. (2013) did a retrospective descriptive study of Forty-five cases out of the 103 cases complicated by fetal pleural effusions during the study period that were managed for primary effusions. Thirty-nine pregnancies continued management, with 14 underwent intervention. The overall survival rate to discharge from the hospital was $51 \%$, including seven survivors after the intervention [4].

In our experience, one of the challenges we faced was fetal anemia cases. The turbid amniotic fluid made the visualization extremely hard even after suction and irrigation. However, we succeeded in blood transfusion in both cases.

The results of this current study are in accordance with other research studies. A prospective study of $99 \mathrm{Rh}$-isoimmunized pregnancies was conducted. Ultrasound-guided intrauterine transfusion was carried out with the primary outcome as fetal survival in-relation-to gestational age and procedure-related factors. The researchers succeeded in blood transfusion for cases with fetal anemia. Intrauterine blood transfusion to the fetus was found to be the only lifesaving therapy, and very useful. The early referral to specialized centers with the expertise of specialized intensive fetal monitoring for early diagnosis of fetal anemia and intrauterine fetal blood transfusion is essential for optimal perinatal outcomes [3].

\section{Limitations of this study:}

This study was a fundamentally descriptive overview of the first fetoscopy role and practice at Al-Hussein hospital. We just used descriptive statistical analysis. Since this study was just a pilot case-series in nature; thus, the sample size was small, which could be considered a limitation of this study. That did not allow us to draw a conclusive interpretation of the results of the study. However, this was
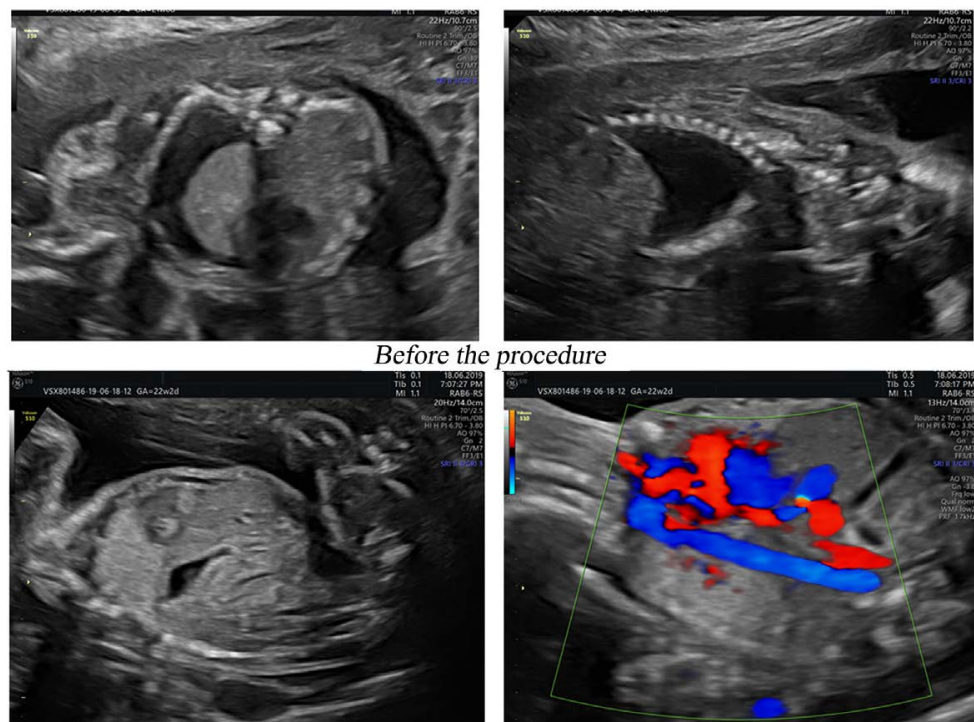

After the procedure

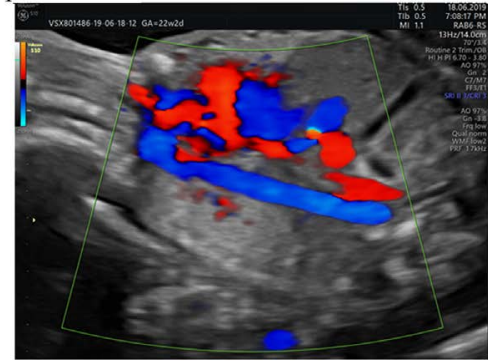

Figure 3. Fetoscopic images: hydrothorax; before and after the procedure. 
because these cases are rare in our center, and this current trial was just an introductory pilot study. For this purpose, we plan to carry out further analytical research studies.

\section{Conclusion}

Fetoscopy can manage PUV and well-selected cases of TTTS, hydrothorax, and fetal anemia. The maternal safety of the procedure is proved.

\section{Acknowledgements}

We want to acknowledge Dr. Emad R. Issak (ClinAmygate) for his efforts in statistical analysis and editing of this manuscript.

\section{Condensation}

In this study, we evaluated the Fetoscopy role in different indications in our center. It is promising and safe tool. It helped to manage well-selected cases with lower urinary tract obstruction (LUTO), twin-to-twin transfusion syndrome (TTTS), hydrothorax and fetal anemia.

\section{Conflicts of Interest}

The authors declare no conflicts of interest regarding the publication of this paper.

\section{References}

[1] Dipika, D., Vatsla, D., Gajatheepan, S.B., Aprajita, S., Aparna, S.K. and Neena, M. (2012) The Art of Fetoscopy: A Step Toward Minimally Invasive Fetal Therapy. The Journal of Obstetrics and Gynecology of India, 62, 655-659. https://doi.org/10.1007/s13224-012-0232-y

[2] Klaritsch, P., Albert, K., Van Mieghem, T., Gucciardo, L., Done, E., Bynens, B. and Deprest, J. (2009) Instrumental Requirements for Minimal Invasive Fetal Surgery. BJOG: An International Journal of Obstetrics \& Gynaecology, 116, 188-197. https://doi.org/10.1111/j.1471-0528.2008.02021.x

[3] Vatsla, D., Deepika, D., Sumana, G., Suneeta, M., Paul, V.K. and Deorari, A. (2010) Treatment of Fetal Anemia in Rh Isoimmunized Pregnancies with Intrauterine Fetal Blood Transfusion. The Journal of Obstetrics and Gynecology of India, 60, 135-140. https://doi.org/10.1007/s13224-010-0019-y

[4] Petersen, S., Kaur, R., Thomas, J.T., Cincotta, R. and Gardener, G. (2013) The Outcome of Isolated Primary Fetal Hydrothorax: A 10-Year Review from a Tertiary Center. Fetal Diagnosis and Therapy, 34, 69-76. https://doi.org/10.1159/000351855

[5] Jancelewicz, T. and Harrison, M.R. (2009) A History of Fetal Surgery. Clinics in Perinatology, 36, 227-236. https://doi.org/10.1016/j.clp.2009.03.007

[6] Kohl, T. (2014) Percutaneous Minimally Invasive Fetoscopic Surgery for Spina Bifida Aperta. Part I: Surgical Technique and Perioperative Outcome. Ultrasound in Obstetrics \& Gynecology, 44, 515-524. https://doi.org/10.1002/uog.13430

[7] Barbachowska, A., Baliś, M., Krzanik, K., Zamlyński, M., Bodzek, P. and Olejek, A. (2017) Intrauterine Fetal Surgery. World Scientific News, 76, 5-15.

[8] Partridge, E.A. and Flake, A.W. (2012) Maternal-Fetal Surgery for Structural Malformations. Best Practice \& Research Clinical Obstetrics \& Gynaecology, 26, 669-682. 
https://doi.org/10.1016/j.bpobgyn.2012.03.003

[9] Deprest, J.A., Devlieger, R., Srisupundit, K., Beck, V., Sandaite, I., Rusconi, S., et al. (2010) Fetal Surgery Is a Clinical Reality. Seminars in Fetal \& Neonatal Medicine, 15, 58-67. https://doi.org/10.1016/j.siny.2009.10.002

[10] Luks, F.I. (2011) New and/or Improved Aspects of Fetal Surgery. Prenatal Diagnosis, 31, 252-258. https://doi.org/10.1002/pd.2706

[11] Gratacós, E. and Deprest, J. (2000) Current Experience with Fetoscopy and the Eurofoetus Registry for Fetoscopic Procedures. The European Journal of Obstetrics \& Gynecology and Reproductive Biology, 92, 151-159. https://doi.org/10.1016/S0301-2115(00)00440-1

[12] Yaffe, H., Yarkoni, S., Rachmilewitz, E.A., et al. (1981) Establishment of a Fetoscopy and Fetal Blood Sampling Program in Israel. Israel Journal of Medical Sciences, 17, 352-354.

[13] Diehl, W. and Bricker, L. (2018) Implementation of Fetoscopic Laser Coagulation for Severe Twin-Twin Transfusion Syndrome in the Middle East. 17 th World Congress in Fetal Medicine, Athens, Greece.

[14] Elbanna, W., Oun, I., Ellatif, E., Hablas, W., Shaikh, W. and Wafa, Y. (2018) Evaluation of Fetoscopy Role in Fetal Surgery and Fetal Medicine. Open Journal of $O b-$ stetrics and Gynecology, 8, 946-957.

[15] Aly, E. and Abd-Manaf, M.H. (2013) Prevalence and Risk Factors for Major Congenital Anomalies among Egyptian Women: A Four-Year Study. The Medical journal of Cairo University, 81, 757-762.

[16] Shawky, R.M. and Sadik, D.I. (2011) Congenital Malformations Prevalent among Egyptian Children and Associated Risk Factors. Egyptian Journal of Medical Human Genetics, 12, 69-78. https://doi.org/10.1016/j.ejmhg.2011.02.016

[17] Papanna, R., Block-Abraham, D., Mann, L.K., Buhimschi, I.A., Bebbington, M., Garcia, E., et al. (2014) Risk Factors Associated with Preterm Delivery after Fetoscopic Laser Surgery for Twin Twin Transfusion Syndrome. Ultrasound in Obstetrics \& Gynecology, 43, 48-53. https://doi.org/10.1002/uog.13206

[18] Korucuoğlu, Ü., Saygi, A.I., Akpak, Y.K., Özdamar, Ö. and Biri, A. (2014) Successful Treatment of Lower Urinary Tract Obstruction with Peritoneal-Amniotic and Vesicoamniotic Shunting. Journal of Acute Disease, 3, 332-334. https://doi.org/10.1016/S2221-6189(14)60071-8

[19] Ruano, R., Yoshisaki, C.T., Giron, A.M., Srougu, M. and Zugaib, M. (2014) Cystoscopic Placement of Transurethral Stent in a Fetus with Urethral Stenosis. Ultrasound in Obstetrics \& Gynecology, 44, 238-240. https://doi.org/10.1002/uog.13293

[20] Martínez, J.M., Masoller, N., Devlieger, R., Passchyn, E., Gómez, O., Rodo, J., Deprest, J.A. and Gratacós, E. (2015) Laser Ablation of Posterior Urethral Valves by Fetal Cystoscopy. Fetal Diagnosis and Therapy, 37, 267-273. https://doi.org/10.1159/000367805

[21] Ruano, R., Yoshisaki, C.T., Salustiano, E.M.A., Giron, A.M., Srougi, M. and Zugaib, M. (2011) Early Fetal Cystoscopy for First-Trimester Severe Megacystis. Ultrasound in Obstetrics \& Gynecology, 37, 696-701. https://doi.org/10.1002/uog.8963

[22] Quintero, R.A., et al. (1995) Percutaneous Fetal Cystoscopy and Endoscopic Fulguration of Posterior Urethral Valves. American Journal of Obstetrics \& Gynecology, 172, 206-209. https://doi.org/10.1016/0002-9378(95)90115-9

[23] Johnson, J.R., Rossi, K.Q. and O’Shaughnessy, R.W. (2001) Amnioreduction versus Septostomy in Twin-Twin Transfusion Syndrome. American Journal of Obstetrics \& Gynecology, 185, 1044-1047. https://doi.org/10.1067/mob.2001.117640 